\title{
Transferência, Convergência e Tradução de Políticas Públicas: A Experiência da Reunião Especializada sobre Agricultura Familiar do Mercosul
}

\author{
Catia Grisa ${ }^{1}$ \\ Paulo Niederle ${ }^{2}$
}

1Professora dos Programas de Pós-graduação em Desenvolvimento Rural (PGDR) e Dinâmicas Regionais de Desenvolvimento (PPGDREDES) da Universidade Federal do Rio Grande do Sul (UFRGS). Porto Alegre, RS, Brasil.

E-mail: catiagrisa@yahoo.com.br; ORCID: https:/ / orcid.org/0000-0001-6685-4875

${ }^{2}$ Professor do Departamento de Sociologia e dos Programas de Pós-Graduação em Sociologia (PPGS) e em Desenvolvimento Rural (PGDR) da Universidade Federal do Rio Grande do Sul (UFRGS). Porto Alegre, RS, Brasil. E-mail: pauloniederle@gmail.com; ORCID: https:/ / orcid.org/0000-0002-7566-5467

\section{INTRODUÇÃO}

Tas últimas duas décadas produziu-se importante literatura so1 bre os processos de difusão, transferência, convergência e tradução de políticas públicas (Oliveira e Faria, 2017; Faria, Coelho e Silva, 2016; Ancelovici e Jenson, 2012; Stone, 2012; Oliveira, 2013; Benson e Jordan, 2011; Hassenteufel, 2008; Evans, 2004; Dolowitz e Marsh, 2000, 1996). De modo geral, esses estudos analisam o modo como ideias, políticas públicas e instrumentos de ação pública (Lascoumes e Le Galès, 2012; 2007) presentes em um contexto político são usados para interpretar problemas e desenvolver ações em outros contextos.

É evidente que tais processos não são particulares das sociedades contemporâneas. Durante as décadas de 1970 e 1980, por exemplo, diversos países latino-americanos foram permeados por projetos de desenvolvimento difundidos e transferidos pelo Banco Mundial (Pereira, 2009). O resultado esperado era a "padronização" (Ancelovici e Jenson, 2012) ou a convergência (Hassenteufel, 2008) das soluções para o desenvolvimento, o que geraria aquilo que Evans (2003) denomina "monocultura institucional em escala global". As mesmas orientações e políticas foram difundidas para diferentes regiões, sendo que, não raro, as justificativas dadas por especialistas

DADOS, Rio de Janeiro, vol.62(2):e20160099, 2019. 
para explicar o "não desenvolvimento" e a ausência de completa convergência enfatizaram as "falhas de governo" existentes nos países subdesenvolvidos (Mitchell e Simmons, 2003). Raramente questionouse a efetividade de transplantar "soluções avançadas" a países com diferentes estruturas institucionais (Chang, 2004). Ademais, em razão da crença na supremacia das "receitas" produzidas no Norte Global, não se conferiu atenção aos resultados mais ocultos, subterrâneos, que permearam a "tradução" (Hassenteufel, 2008) das instituições em contextos locais (Long, 2001).

Ainda que a difusão de ideias e de ações públicas não seja recente, podemos observar mudanças quantitativas em sua ocorrência com o avanço da globalização (Castels, 2005) e, mais recentemente, também mudanças qualitativas em virtude dos movimentos de redistribuição do poder global (Faria, 2012) - o que implicou inclusive a reorganização de organizações multilaterais e arenas públicas internacionais ao longo dos anos 2000 (Sabourin, Samper e Massardier, 2015; Dolowitz e Marsh, 2000).

Uma das novidades nesse debate foi a profusão de pesquisas apontando para novos modelos de governança e interação com Estados naquilo que convencionalmente passou a ser chamado de "Sul Global" (Beard, Miraftab e Silver, 2008). Alguns autores sugerem que, mais do que uma alteração dos agentes políticos - com a crescente participação dos "ausentes e emergentes" (Santos, 2002), inclusive na direção dos fóruns e organizações multilaterais -, a ideia de Sul Global traduziu-se mais exatamente na formação de uma nova epistemologia, a qual se expressaria na emergência de novos modelos e métodos de disseminação internacional de políticas públicas. Em vez da imposição da "boa governança" via diferentes mecanismos de pressão mais ou menos legitimados internacionalmente (restrição no acesso a recursos, apoio político, militar e financeiro etc.), os novos modelos primariam: (a) pela proliferação, abertura e democratização dos fóruns multilaterais; (b) pelo engajamento da sociedade civil em espaços outrora controlados por uma racionalidade técnico-mercantil; (c) pela alteração do modus operandi das próprias organizações multilaterais.

No caso do Brasil, a agenda da agricultura familiar e da segurança alimentar e nutricional constitui uma das áreas em que o país mais capitaneou esforços na difusão e transferência internacional de políticas públicas, promovida notadamente no âmbito das relações sul-sul (Grisa e Schneider, 2015). Vários estudos já abarcaram o protagonis- 
mo internacional do país na área, mas a maior parte deles focaliza os resultados das políticas e programas adaptados para implementação em outros países, tais como o Programa de Aquisição de Alimentos (PAA) África e o Pró-Savanas (Scoones et al., 2016; Milhorance, 2013; Pinho, 2013; Goulet, Gabas e Sabourin, 2013; Castro e Goulet, 2011; Camacho, 2011). Mais raras são as pesquisas dedicadas a observar os espaços de disseminação das políticas, o que foi transferido e como isso ocorreu. São esses os aspectos da construção da Reunião Especializada sobre Agricultura Familiar (REAF) do Mercosul que nos propomos a abordar neste artigo.

Embora constitua um espaço formal do bloco sul-americano, a REAF é um dos poucos fóruns multilaterais com ampla participação da sociedade civil. Criada em 2004, há mais de uma década ela capitaneia um processo de construção e disseminação de políticas para a agricultura familiar, não apenas entre os países do Mercosul Ampliado, mas com uma incidência importante em toda América Latina. Isso lhe permitiu projetar-se no cenário global como um modelo de governança multilateral participativa para a produção de políticas públicas (FIDA, 2013; CELAC, 2014; FAO, 2015).

O objetivo aqui é analisar o modo como ideias, políticas e instrumentos de ação pública para a agricultura familiar foram transferidos no âmbito da REAF, enfatizando os atores envolvidos e suas relações no processo de decisão, bem como o modo como as políticas convergiram ou foram traduzidas nos espaços nacionais. Para essa finalidade, em termos metodológicos, o trabalho baseia-se em participação e observação das reuniões regionais da REAF, pesquisa documental e 42 entrevistas realizadas com ministros, policymakers, lideranças sociais, pesquisadores e consultores internacionais de todos os países do bloco ao longo dos anos de 2014 e 2015.

O artigo está estruturado em cinco seções para além desta introdução e das considerações finais. A primeira, de cunho mais conceitual, apresenta uma breve discussão sobre os principais conceitos e noções abordados na análise. As duas seções seguintes discutem a constituição da REAF enquanto espaço para a construção de políticas para a agricultura familiar no Mercosul. As duas seções finais apresentam casos escolhidos para ilustrar o processo de tradução das políticas públicas: os registros nacionais da agricultura familiar e os programas de compras públicas. 


\section{ELEMENTOS CONCEITUAIS DO PROCESSO DE TRANSFERÊNCIA, CONVERGÊNCIA E TRADUÇÃO DAS POLÍTICAS PARA A AGRICULTURA FAMILIAR NA REAF}

Difusão, transferência, convergência e tradução são algumas das noções recorrentes na literatura que discute o modo como ideias, formatos e instrumentos de políticas públicas são disseminados de um contexto para outro. Embora as diferentes noções apresentem similaridades, complementaridades e pontos de sombreamento, elas também repercutem distintas ênfases ou compreensões sobre o assunto ${ }^{1}$.

A noção de difusão de política pública foi inicialmente desenvolvida nos Estados Unidos, tendo como um dos principais expoentes Jack L. Walker (1969), bastante influenciado pelo estudo clássico de Everett Rogers, Diffusion of innovations ${ }^{2}$. De modo geral, os autores identificados com essa abordagem procuram evidenciar as razões pelas quais alguns governos adotam determinadas políticas enquanto outros não o fazem, bem como o modo e a velocidade com que as inovações se disseminam (Oliveira e Faria, 2017; Coelho, Cavalcanti e Turgeon, 2016). Enfatizando os determinantes internos e externos e a tendência de adoção de uma prática ou política pública de um local para outro, os autores examinam como a adoção prévia por uma população (organização) altera a probabilidade de adoção pelas demais. Focaliza-se, portanto, os elementos mais cognitivos e simbólicos do processo, e menos as dinâmicas políticas envolvidas e as relações de poder, ou ainda o conteúdo da política pública difundida (Hassenteufel et al., 2017; Stone, 2012). Ademais, como pontuam Stone (2012), Knill (2005) e Levi-Faur e Vigoda-Gadot (2004), prevalece nessa abordagem a ideia de que a criação ou as mudanças nas políticas públicas ocorrem por osmose, contágio ou propagação de modelos ou práticas de uma fonte comum ou ponto de origem, em um processo mais voluntário, pouco permeado por interesses ou pressões políticas. Por essas razões, geralmente a aproximação difusionista é criticada por ser "politicamente neutra" (Levi-Faur e Vigoda-Gadot, 2004:6).

Por sua vez, a abordagem mais estrutural de transferência de política pública concede mais atenção à utilização instrumental/funcional do conhecimento ou de lições aprendidas em outros países, bem como às relações de poder que permeiam o processo. Aqui, a transferência é situada entre um contínuo de voluntarismo (escolha racional) e coerção, geralmente envolvendo elementos de ambos. Mais frequente 
entre pesquisadores europeus (cf. Stone, 2012), essa abordagem ganhou impulso principalmente com os estudos de David Dolowitz e David Marsh (Dolowitz, 2003; Dolowitz e Marsh, 2000; 1996).Os autores construíram um modelo de análise bastante esquemático - incorrendo inclusive no risco de tornar sua aplicação mecânica, prescritiva e descritiva (McCann e Ward, 2012; 2013) -, organizado em sete questões, quatro delas destacadas a seguir devido a sua importância para, posteriormente, analisarmos a experiência da REAF.

A primeiraquestão aborda as diferentes motivações envolvidas na transferência de um programa, política ou arranjo institucional, situando-as, como destacado, em um continuum entre "atitudes voluntárias" e "elementos coercitivos" (Dolowitz, 2003). Essa ideia é utilizada para evitar o equívoco de considerar que escolhas voluntárias sejam baseadas em respostas racionais e perfeitas, mas tampouco menospreza o cálculo utilitário como um dos componentes da tomada de decisão (Callon, 1998). Por sua vez, no outro extremo (coerção), destaca-se a atuação de organizações transnacionais, blocos econômicos, agências internacionais, ou mesmo de países na imposição de medidas aos governos como condição para suporte a programas e políticas públicas.

A segunda, diz respeito aos atores protagonistas no processo de transferência. Em suas pesquisas, Dolowitz e Marsh (2000) identificaram algumas categorias de atores envolvidos nos processos de transferência de política pública, sendo eles partidos e políticos eleitos, burocratas, grupos de interesses, empreendedores políticos, experts, corporações transnacionais, think tanks, organizações governamentais supranacionais, organizações não governamentais e consultores. Essa amplitude de atores é particularmente importante porque expande a análise para além das relações bilaterais entre Estados-nação, opção prevalecente nos estudos iniciais sobre transferência (McCann e Ward, 2013, 2012; Stone, 2004) que repercutiu numa espécie de "nacionalismo metodológico" (Stone, 2004). A partir dessa reinterpretação, compreende-se que a ação transferida pode ter sua origem em múltiplos contextos, escalas e atores (Maluf, Santarelli e Paulino, 2016; Oliveira, 2013).

A terceira questão refere-se aos elementos transferidos: metas, objetivos, conteúdos, instrumentos, programas, instituições, ideologias, ideias, atitudes e lições (Dolowitz, 2003). Segundo Benson e Jordan (2011), inicialmente os estudos privilegiaram a análise da transfe- 
rência de instrumentos, instituições e programas entre governos ou entre diferentes níveis de governo ('hard' transfer). Os novos estudos passaram a dar maior importância para a disseminação de ideias, ideologias, noções e conceitos ('soft' transfer).

Finalmente, a quarta questão que nos interessa trata dos "graus de transferência". Para Dolowitz e Marsh (2000), a transferência não é um processo de "tudo ou nada", podendo apresentar diferentes graus de similitude em relação ao original: cópia, emulação, combinação ou inspiração. Cópia envolve a transferência completa e direta de políticas públicas, programas ou ações; emulação refere-se à transferência de ideias que estruturam o programa ou a política pública; combinação diz respeito à mistura de diferentes políticas públicas; e inspiração é o caso de uma política que inspira o surgimento de outra, ainda que distante da proposta original. Os graus variam entre políticas públicas, contextos sociais, conjunturas políticas, relações de poder (transferência impositiva e/ou voluntária) e atores sociais envolvidos.

Utilizada principalmente para a análise das relações entre dois países ou entre distintas escalas administrativas dentro do mesmo país, a abordagem de transferência apresenta limitações para a compreensão de similaridades entre políticas públicas adotadas em vários países (Hassenteufel, 2005; Knill, 2005). Em virtude disso, ganhou espaço na literatura a noção de "convergência", definida como "um processo dinâmico de aproximação entre políticas públicas conduzidas em países (ou territórios) diferentes"(Hassenteufel e Maillard, 2013:12). Em outras palavras, convergência significa a adoção ou a aproximação entre políticas públicas similares em diferentes países ou blocos regionais (Hassenteufel, 2008).

Mesmo assim, os estudos sobre convergência também apresentam limites para compreender o modo como políticas públicas são traduzidas em espaços locais. Suas diversas formas de expressão em contextos distintos possivelmente não são apenas fruto de convergência parcial ou limitada, ou de transferência desinformada, incompleta ou inapropriada (Dolowitz e Marsh, 2000), mas, cada vez mais, da "construção híbrida mesclando elementos externos e internos" (Hassenteufel, 2005:128). Desse modo, enquanto a noção de convergência pode conduzir a uma ênfase excessiva na harmonização, a abordagem de transferência negligencia os conflitos entre atores (recursos que dispõem; estratégias, discursos e narrativas que mobilizam; es- 
paços onde atuam), os modos de recepção dos elementos das políticas transferidas (processos de tradução) e a forma como se misturam elementos transferidos e elementos preexistentes (processo de hibridação) (Hassenteufel, 2008; 2005).

Em virtude de tais limitações, ganha importância a noção de "tradução", recuperada pelos autores a partir dos estudos de Callon (1984) e Latour (1994) sobre redes sociotécnicas, os quais, por sua vez, herdaram o conceito da filosofia de Serres (1993). Próxima aos conceitos de inspiração, emulação e combinação de Dolowitz e Marsh (2000), bem como da noção de mutação de McCann e Ward (2013; 2012), tradução corresponde a uma atividade de recriação (e não somente importação ou difusão) de orientações, conteúdos e instrumentos de política pública (Hassenteufel et al., 2017; Oliveira e Faria, 2017; Hassenteufel, 2008; Lascoumes, 2006). A análise da criação ou das mudanças nas políticas públicas implica, portanto, compreender a tradução do conteúdo da ação pública, a forma de agir e de se mobilizar dos atores (os tradutores), e o contexto onde o processo ocorre (Hassenteufel, 2005).

Nessa abordagem, os atores políticos são indissociavelmente "atores" que conduzem ações e "intérpretes" que a elas atribuem novas significações. Sobretudo quando se trata de atores oriundos de regiões ou países com culturas muito diferentes, para além das regras e instrumentos que conformam as políticas públicas, o processo de tradução é fortemente influenciado por mecanismos mais informais de linguagem (expressões, gestos, condutas). Continuamente reinterpretados no curso das interações sociais, tais mecanismos frequentemente são responsáveis por uma espécie de "traição" entre o que é interpretado e o conteúdo originalmente imaginado. Assim, em vez de propriedades substanciais derivadas de estruturas nebulosas, as políticas se estabelecem como propriedades verdadeiramente relacionais, em que a tradução se revela um processo de criação de novas associações, inovação e produção de hibridismos, ou, como destaca Serres (1993), de "mestiçagem".

Para a análise do caso da REAF, em vez de enquadrar a realidade social por meio de apenas uma das abordagens apresentadas nesta seção, o artigo procura colocá-las em diálogo, considerando suas distintas ênfases e complementaridades. Como discutiremos a seguir, a REAF é um espaço para a transferência voluntária de políticas públicas para a agricultura familiar que, embora tenha conduzido a um processo de convergência das ações na agenda regional, oferece es- 
paço para a tradução das ideias e instrumentos de políticas públicas nos espaços locais.

\section{A CONSTRUÇÃO DE UM ESPAÇO PARA A AGRICULTURA FAMILIAR NO MERCOSUL}

O Mercosul foi constituído em 1991 por meio do Tratado de Assunção, o qual estabeleceu como objetivo a criação de uma zona de livre comércio que implicaria em: a) livre circulação de bens, serviços e fatores produtivos; $b$ ) tratamento alfandegário e tributário similar em transações com países terceiros; c) coordenação de políticas macro-econômicas e setoriais; d) compromisso dos Estados em harmonizar suas legislações nas áreas pertinentes com vistas a fortalecer o processo de integração. Tais elementos respondiam à nova geopolítica dos mercados globais em um contexto de expansão do neoliberalismo que impunha a abertura comercial. Contudo, o Mercosul nasceu em meio a tensões e interesses divergentes, os quais se aprofundaram no decorrer do tempo e com as mudanças nas coalizões políticas à frente dos governos nacionais.

A partir dos anos 2000, os novos governos de centro-esquerda, os quais incorporaram muitas lideranças sociais à burocracia do Estado, passaram a conferir amparo institucional para a crítica aos processos de liberalização e, ao mesmo tempo, propuseram uma nova estratégia de inserção na economia globalizada, focada na articulação entre os países da América Latina e no fortalecimento de um novo modelo de integração para o Mercosul. Como destaca o excerto da entrevista concedida por um ex-ministro brasileiro a seguir, em vez da agenda liberal de ajustes estruturais, desregulamentação e privatização, tornou-se prioritário o fortalecimento dos Estados. O foco passou a ser o fomento de políticas de crescimento econômico com inclusão produtiva, participação social e redução das assimetrias regionais (Vigevani e Ramanzini Jr., 2014).

A REAF nasceu de uma conjuntura política que se criou no Brasil e muito especialmente no Mercosul. Nasceu de uma visão contra uma integração pautada pelo livre comércio, ou seja, contra a ALCA do jeito que ela estava colocada, e a partir de uma visão de integração na região a partir dos povos, a partir das pessoas. [...] A gente começou a se perguntar: se nós não queremos a integração do ponto de vista comercial do jeito que a ALCA estava sendo proposta, qual é a integração que nós queremos?[...] A gente 
começa a partir das políticas públicas, do fortalecimento do Estado, e da ideia de cooperação, integração e diálogo sobre políticas públicas e também sobre uma relação comercial diferenciada. (Ex-Ministro do Desenvolvimento Agrário do Brasil. Excerto de entrevista concedida em março de 2015).

Sendo assim, o Mercosul não poderia mais ser visto apenas como um acordo comercial. As trocas econômicas tornaram-se um elemento específico (ainda predominante) em uma teia de mudanças institucionais que incluía preocupação com a integração política, social e cultural. Passou-se a falar em "Mercosul Social e Participativo" (Brasil, 2008) e houve preocupação crescente com a ampliação da solidariedade entre os países sul-americanos, o que contribuiu para ampliar os processos de intercâmbio, convergência e aperfeiçoamento de políticas públicas, desenvolver uma nova geração de políticas de desenvolvimento com inclusão social, gerar mecanismos para combater as assimetrias econômicas intrabloco e fortalecer os fóruns públicos e os processos de participação social.

A agricultura sempre foi um dos setores mais presentes na agenda de negociações do Mercosul. Nos anos 1990, as medidas de abertura comercial decorrentes da assinatura do acordo desencadearam um processo de reestruturação dos sistemas agroindustriais e de desestruturação dos sistemas agrários locais e, como consequência, a crise da pequena produção de base familiar, exposta abruptamente à concorrência de produtores estrangeiros mais competitivos (Wilkinson, 2008). A crescente insatisfação social com as medidas adotadas fortaleceuas lutas dos movimentos sociais na demanda por políticas diferenciadas, os quais passaram a reivindicar atenção particular à agricultura, especialmente àquela realizada em pequena escala (Romano, 1996).

Naquele momento, ganhou evidência a atuação da Confederação Internacional de Organizações de Produtores Familiares do Mercosul Ampliado (Coprofam). Constituída em 1994 e atualmente formada por 12 organizações sindicais de sete países, esta entidade-rede tornou-se a principal interlocutora dos pequenos produtores na região. Foram as consequências do processo de abertura comercial, associados aos bloqueios impostos à participação das organizações da agricultura familiar nas estruturas institucionais do Mercosul, que catalisaram o surgimento da articulação regional das organizações da agricultura familiar. Apesar de suas inúmeras diferenças, elas 
unificaram-se em torno de um objetivo comum: o reconhecimento de que seus países abrigavam distintas formas de fazer agricultura, incluindo unidades familiares que, em vista de suas características particulares, demandavam um tratamento diferenciado dos Estados nacionais e do bloco em seu conjunto.

Para discutir as implicações setoriais da abertura comercial, em 1995 o Grupo Mercado Comum, instância executiva do bloco, instituiu um conjunto de órgãos assessores, dentre os quais o SGT 8, Subgrupo de Trabalho que trata da agricultura. Contudo, esse espaço incluiu debates sobre os impactos da integração regional para agricultores familiares de forma marginal, tendo prevalecido questões comerciais que afetavam mais diretamente grandes grupos agroindustriais. Com efeito, o agravamento da vulnerabilidade social e econômica dos pequenos produtores desencadeou a necessidade de uma ação mais incisiva. Em 2003, como resultado de um seminário regional intitulado As Assimetrias nas Políticas Econômicas e Agrícolas dentro do Mercosul, a Coprofam entregou a "Carta de Montevidéu" ao Conselho do Mercado Comum (CMC), instância que coordena politicamente o processo de integração. Marco fundamental na história da REAF, o documento demanda "a criação de um grupo 'ad hoc' especializado no marco do SGT8, com participação de representantes dos governos e da Coprofam, que (...) proponha uma agenda para a política diferencial para a agricultura familiar".

Um interlocutor importante da Coprofam foi o Programa Fida Mercosul, estabelecido pelo Fundo Internacional de Desenvolvimento Agrícola (FIDA) com a finalidade de apoiar a institucionalização de novas políticas de desenvolvimento rural e de redução da pobreza no contexto sul-americano. Essa organização desencadeou um processo de aproximação entre os governos e as organizações sociais do meio rural da região. Desde então, alguns países passaram a contar com programas públicos amparados financeira e tecnicamente pelo FIDA, muitos dos quais estão na origem das atuais políticas para a agricultura familiar. Mas, como destacado a seguir, ainda faltava um ator essencial para a construção do desenho organizacional e institucional da REAF, a saber, o governo brasileiro.

Você tinha de fato um tecido social que estava procurando capitalizar, discutir e criar espaços dentro do Mercosul para discutir uma agenda diferente de agricultura familiar, e a COPROFAM teve um papel 
muito importante nisso desde o final dos anos 1990. [...] Ela já estava demandando esse tipo de espaço, mas não era exatamente a REAF. A construção institucional da REAF foi muito estruturada a partir do governo brasileiro, pensando também no Programa FIDA Mercosul, que já existia. Havia uma semente que já estava plantada. [...] Se eu for pensar o desenho institucional, a colocação disso dentro do Mercosul e a briga diplomática que teve que ser feita, isso foi, sobretudo, a partir do governo brasileiro, mas isso não funcionaria sem a demanda e a pressão social que já existia, sem a articulação que a Coprofam conseguiu constituir dentro dos demais países, pressionando os demais governos para aceitar isso também. E também não seria possível nada disso se não tivesse os mecanismos financeiros, técnicos e de sustentação do Programa FIDA Mercosul. (Ex-Coordenador Nacional Alterno do Brasil na REAF. Excerto de entrevista concedida em abril de 2015).

Foi o Ministério Brasileiro das Relações Exteriores (MRE) que articulou a leitura da Carta de Montevidéu às demais autoridades regionais, ato realizado pelo então presidente da Coprofam e ex-presidente da Confederação Nacional dos Trabalhadores na Agricultura (Brasil). A reação do CMC foi incumbir ao governo brasileiro o encargo de apresentar uma proposta que pudesse se adequar à estrutura institucional do Mercosul. A tarefa foi repassada ao Ministério do Desenvolvimento Agrário (MDA) que, com apoio do MRE, desenhou o primeiro formato de uma Reunião Especializada, apresentado na Reunião Ordinária do GMC em fevereiro de 2004. Constituiu-se, assim, a REAF Mercosul como um espaço regional para discussão e construção de políticas para a agricultura familiar, colocando Estado e sociedade civil em diálogo.

\section{A ESTRUTURA DO FÓRUM PÚBLICO}

A criação da REAF não foi um processo simples e pacífico. Uma das primeiras dificuldades enfrentadas foi a interpretação predominante entre alguns governos de que, em seus países, existia uma única agricultura - que resultava no privilégio concedido aos setores do agronegócio (Ramos et al., 2014). Ademais, para muitos governos, a noção de "agricultura familiar" soava como a transferência de uma definição, talvez coerente ao contexto brasileiro, mas inadequada à realidade de suas comunidades campesinas e indígenas. Também havia interpretações segundo as quais, sob a bandeira da agricultura fa- 
miliar, estaria oculto algum tipo de estratégia comercial em benefício de determinados grupos, cadeias produtivas e territórios.

Assim, antes mesmo da produção de instrumentos de políticas públicas, tornou-se fundamental rever paradigmas e construir convergências conceituais sobre as formas familiares de produção na agricultura. Uma vez organizada, a REAF tornou-se um espaço para discussão, difusão, transferência (soft transfer) e produção de ideias e conceitos convergentes sobre a agricultura familiar, sua relevância socioeconômica e sua diversidade, ou seja, suas particularidades locais.Antes relegada à representação de uma "pequena agricultura", marginal e incapaz de constituir uma via para a modernização do meio rural, as agriculturas familiares passaram a ser vistas como modelos inovadores de desenvolvimento rural sustentável (Grisa e Schneider, 2015; Cravioti, 2014). De forma convergente, as agriculturas familiares, campesinas e indígenas não apenas deixaram de ser vistas como sinônimo de pobreza e insegurança alimentar, como se tornaram parte ativa da solução para esses problemas (FAO, 2014).

Essa mudança de paradigma catalisou os diálogos regionais e os fez convergir para o desenho de uma nova geração de políticas de desenvolvimento rural. Com efeito, ao longo dos últimos dez anos, vários países construíram um amplo conjunto de políticas especificamente voltadas ao segmento, traduzindo os elementos conceituais às particularidades locais. Mesmo naqueles países onde a criação de políticas foi freada pela resistência imposta por grupos de interesse ligados à agricultura patronal e empresarial (Riella, 2002), a REAF conseguiu cumprir um papel central para legitimar lutas por reconhecimento. Atualmente, as próprias organizações sociais que, inicialmente, foram críticas ao Mercosul, utilizam o fórum como elemento de reforço discursivo nas disputas por políticas e nas lutas por afirmação de suas identidades sociopolíticas.

Formalmente, a REAF constitui um órgão auxiliar e assessor do GMC. Suas deliberações constituem propostas e recomendações sobre políticas que, para se tornarem efetivas, necessitam aprovação das instâncias superiores (GMC ou CMC). Uma vez acatadas, passam a compor um conjunto de instrumentos normativos (Recomendações, Decisões, Resoluções e Diretrizes ${ }^{3}$ ) que orientam as ações dos Estados membros (Argentina, Brasil, Paraguai, Uruguai e Venezuela, 
quando da realização da pesquisa) e associados (Bolívia, Chile, Colômbia, Equador e Peru).

A principal instância de decisão da REAF é a Plenária Regional, a qual ocorre bianualmente, é geralmente sediada no país que detém a presidência pro tempore do bloco (alternada a cada seis meses) e envolve a participação de atores governamentais e da sociedade civil. A estrutura organizacional também envolve o trabalho intenso das Seções Nacionais. Consideradas elemento essencial do ponto de vista político e metodológico, elas são estabelecidas em todos os países, mas com formatos e modos de organização singulares que traduzem as características de cada contexto. Nas Seções Nacionais são debatidos os temas da pauta com vistas a orientar a intervenção dos representantes, do governo e da sociedade civil, que ali são escolhidos para representar o país na Plenária Regional.

Figura 1

A estrutura de governança da REAF Mercosul

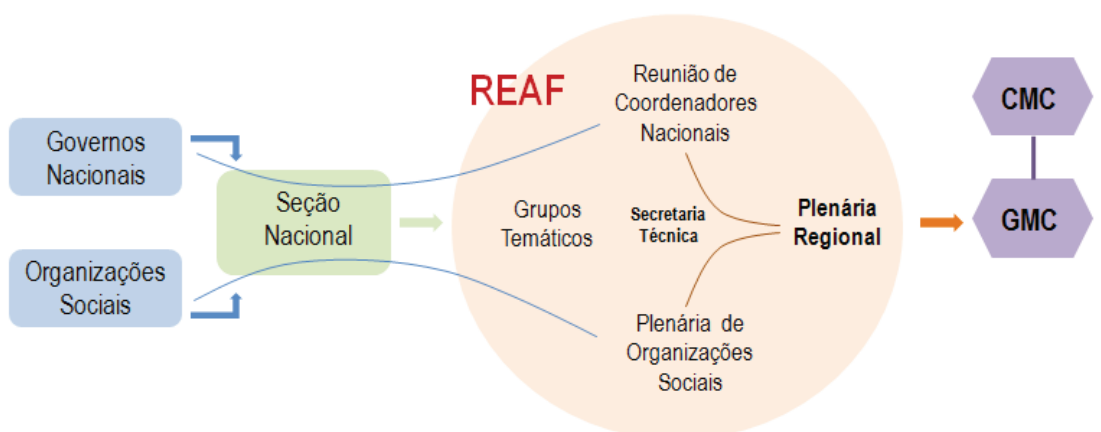

Fonte: Niederle (2016).

Outro espaço de diálogo são os Grupos Temáticos (GT), criados para dinamizar as discussões em torno de temas considerados prioritários e convergentes na agenda. Eles são igualmente formados por delegados escolhidos dentre representantes oficiais e membros da sociedade civil. Atualmente, a REAF abriga cinco grupos: (i) Políticas fundiárias, acesso à terra e reforma agrária; (ii) Facilitação do comércio; (iii) Equidade de gênero; (iv) Gestão do risco e mudança climática; e (v) Juventude Rural. Complementarmente, também foi criado um Gru- 
po Técnico específico para discutir os Sistemas de Registro Nacional da Agricultura Familiar.

Antecedendo a Plenária Regional, ocorrem debates em dois outros espaços. Um deles é a Plenária das Organizações Sociais, que consiste no diálogo entre os representantes da sociedade civil organizada dos diferentes países, a partir do qual é redigido um documento que reúne as principais reivindicações dos agricultores familiares, camponeses e indígenas no que diz respeito ao desenho das políticas públicas. Encaminhado para leitura na Plenária Regional, o documento contribui para balizar os diálogos entre representantes dos governos e dos movimentos sociais.

Paralelamente às discussões da sociedade civil ocorre a Reunião de Coordenadores Nacionais. Ela constitui o fórum regional onde os representantes oficiais escolhidos para representar os governos de cada país perante uma instância formal do Mercosul debatem e selam compromissos para a condução dos diálogos. Ali são discutidos, por exemplo, o programa da sessão plenária final, a metodologia dos debates, as atividades levadas a cabo coletivamente entre os governos e as propostas de cooperação entre a REAF e organizações multilaterais. Os acordos definidos são igualmente submetidos à Plenária Regional, podendo ser objeto de contestação por parte dos movimentos sociais.

Até 2015, a REAF acumulou cinco "ciclos". Cada ciclo corresponde ao período necessário para que se cumpram as presidências de todos os países membros, substituída a cada seis meses. O primeiro ciclo priorizou a identificação de temas convergentes entre distintos atores, incluindo movimentos sociais. A partir disso foi possível extrair os eixos para formar os GTs e também avançar em algumas ações específicas, sobretudo na identificação das políticas existentes em cada país, na mensuração da participação econômica da agricultura familiar, nas análises sobre cadeias produtivas prioritárias no contexto regional, além de seminários e reuniões sobre temas específicos.

Mas foi a construção de entendimentos políticos entre atores e organizações que não possuíam relações recorrentes que efetivamente marcou o primeiro ciclo da REAF. Com exceção da articulação entre os movimentos sociais vinculados à Coprofam, os demais atores que iniciaram os diálogos na REAF possuíam convivência esporádica, possibilitada pela presença simultânea em alguns fóruns regionais ou pe- 
las trocas de experiências, igualmente esporádicas, entre os governos na área de gestão das políticas públicas. Em virtude disso, conforme nossos entrevistados, o que prevalecia naquele momento ainda eram as desconfianças sobre os princípios, os objetivos, o modo de funcionamento e as formas de participação do novo espaço coletivo.

\begin{abstract}
No início, como ninguém conhecia ninguém, todo mundo desconfiava de todo mundo. $\mathrm{O}$ medo que se tinha era isto: que por detrás daquilo estivesse alguma coisa para facilitar o comércio para a agricultura de alguém. Então, as atas das reuniões acabavam de ser feitas às 4 horas da manhã do dia seguinte. O que se quer dizer com isso? O que significa essa vírgula? Isso em espanhol fica como? Então, eu acho que uma boa e importante conquista que a gente teve foi essa confiança política. (Professor e assessor do MDA-Brasil. Excerto de entrevista concedida em dezembro 2014).
\end{abstract}

Logo se tornou evidente que a REAF não era o tipo de fórum que se colocaria em movimento por decreto ou coerção. As primeiras plenárias foram fundamentais para construir a confiança e os entendimentos imprescindíveis para o diálogo político. Um dos principais temas discutidos foi o modelo de participação social. Em vista das experiências dos conselhos sociais que estavam em funcionamento no Brasil, o governo brasileiro fez pressão para que as organizações da sociedade civil ocupassem a mesma mesa dos representantes oficiais, o que causou estranhamento à lógica formalista do Mercosul ${ }^{4}$, bem como à chancelaria de outros países, sobretudo daqueles que enfrentavam forte oposição social.

As bases de diálogo e de tomada de decisão foram pautadas pela construção de entendimentos comuns entre os governos e as organizações sociais. Formalmente, qualquer governo pode obstar a aprovação de determinada medida, o que faz com que as decisões ocorram por consenso - assumindo, portanto, formatos mais voluntários que coercitivos. No entanto, há trocas políticas que tornam o processo muito mais complexo, mostrando que a construção dos consensos envolve acordos e negociações. Segundo Carvalho (2011), a própria criação da REAF envolveu uma troca política entre os governos do Brasil e da Argentina, na medida em que este teria condicionado a aprovação da REAF à criação de uma Reunião Especializada de Defensores Públicos Oficiais - ambas aprovadas na mesma reunião do CMC. Por sua vez, embora não tenha poder de veto, a sociedade civil 
também é consultada e, em geral, somente são levadas adiante ações que tenham anuência das organizações sociais.

O segundo ciclo marcou avanços mais expressivos na formulação de projetos que, em seguida, serviram de esteio para a redação das primeiras propostas de recomendação enviadas ao GMC/CMC. Entre o final de 2006 e meados de 2008, foi produzida uma série de documentos técnicos que orientaram as discussões regionais em temas como reconhecimento e identificação da agricultura familiar, integração e facilitação do comércio para os produtos dosegmento, seguro rural e gestão de risco, educação não formal de jovens rurais e políticas de igualdade de gênero.

O terceiro ciclo consolidou os entendimentos políticos. Embora a maioria dos temas já estivesse presente desde o princípio das discussões nos GTs, nota-se que os compromissos foram institucionalizados em várias proposições levadas ao GMC, muitas das quais foram acolhidas. $\mathrm{O}$ ciclo também foi marcado por discussões sobre os limites organizacionais e institucionais que poderiam colocar em risco a perenidade da REAF. Com efeito, parte da discussão voltou-se à construção do Fundo de Agricultura Familiar (FAF). Formado por aportes financeiros dos países membros e associados, o fundo é utilizado para garantir a participação dos representantes da sociedade civil e para sustentar as atividades da Secretaria Técnica.

Finalmente, estabilizada a nova arquitetura institucional e operativa da REAF, o quarto e, sobretudo, o quinto ciclo revelaram um passo a frente na construção de políticas convergentes, na sua transferência e tradução nos países do bloco. Destacaram-se naquele momento os avanços para a criação dos Registros Nacionais da Agricultura Familiar, o controle e regulamentação da estrangeirização da propriedade da terra, os programas de formação da juventude rural, o programa regional de fortalecimento das políticas de igualdade de gênero e o tema das compras públicas de alimentos.

Essa breve sociogênese da REAF possibilita compreender preliminarmente quais são os principais atores, como as decisões são tomadas e quais ideias, noções e políticas públicas são transferidas. Contudo, visando adentrar os processos de transferência de políticas e instrumentos de ação pública, as próximas seções focalizam dois exemplos que, em diferentes momentos históricos, estiveram no centro das dis- 
cussões: a construção dos Sistemas Nacionais de Registro da Agricultura Familiar e os Programas de Compras Públicas. A escolha deve-se às diferentes configurações que o processo de transferência assume em cada situação.

\section{DAS DEFINIÇÕES NORMATIVAS AOS SISTEMAS NACIONAIS DE REGISTRO DA AGRICULTURA FAMILIAR: AS TRADUÇÕES NECESSÁRIAS}

O desenho de políticas públicas implica a definição de um público beneficiário. Sendo assim, um dos primeiros passos da REAF foi construir parâmetros convergentes de identificação da agricultura familiar, estabelecendo critérios mínimos que permitissem uma intervenção mais equitativa entre os países membros, sem desconsiderar a heterogeneidade. Como destacaram nossos interlocutores, além de permitir a identificação do público, uma definição comum passaria a legitimar não apenas a atuação da REAF, mas dos próprios órgãos estatais que foram criados em cada país para responder às reivindicações de políticas públicas para a agricultura familiar, assim como das organizações sociais a que representam politicamente.

Tem um tema central que é o avanço que nós tivemos nos países para o reconhecimento da agricultura familiar do ponto de vista formal/técnico. [...] Quando a gente se convenceu de que a agricultura familiar existia e era diferente, o grande desafio era controlar isso. Aí vem o tema da definição da agricultura familiar e a questão do registro. Este se torna um tema fundante porque é a base para tudo. Se você vai fazer uma política dirigida, tem que saber a quem dirigir. (Ex-Ministro do Desenvolvimento Agrário do Brasil. Excerto de entrevista concedida em março de 2015).

O primeiro passo que eu creio que foi fundamental é ter colocado na mesa de discussão a importância e a pertinência de ter um registro. Quando começamos a conversar com as organizações e falamos "vamos fazer um registro porque necessitamos saber quantos são, onde estão e quantos representam", as organizações se sentiram questionadas. [...] Mas, quando iniciamos a desenhar os instrumentos, quando iniciamos a ver os temas dos orçamentos, se deram conta de que os recursos são escassos e é necessário focalizar, é necessário priorizar, e a melhor forma é identificar os sujeitos da agricultura familiar. (Gestor público do Governo do Chile. Excerto de entrevista concedida em dezembro de 2014). 
Os parâmetros institucionalizados pela Resolução GMC nº 25/2007 exigem: a predominância da mão de obra familiar nas atividades produtivas, limitando a contratação; a responsabilidade familiar pela gestão e trabalho; e o uso de recursos compatíveis com a capacidade de trabalho, atividade desenvolvida e tecnologia utilizada. Embora seja uma Resolução (de caráter obrigatório), são parâmetros genéricos que permitem abarcar as múltiplas formas de agricultura familiar do Mercosul. Como destaca um dos atores que esteve à frente da Secretaria Técnica da REAF nos primeiros anos, logo se viu que a única maneira de avançar para um entendimento comum era construir uma noção suficientemente ampla, a partir da qual os países teriam liberdade para definir ou traduzir critérios mais específicos, para dar conta da heterogeneidade.

Eu creio que a virtude da definição de agricultura familiar que fez a REAF é que ela é muito pragmática e muito política, e que pode ser adaptável e adaptada a distintas circunstâncias e a distintos países ou regiões. Porque ela define uma série de cinco ou seis características que tem que cumprir a agricultura familiar e deixa livre a ponderação e a parametrização das mesmas à realidade de cada país e de cada região. Isso permite ter uma definição guarda-chuva ou compreensiva e, por outro lado, abre a possibilidade de reconhecer a heterogeneidade dentro deste grande conceito. (Ex-Secretário Técnico da REAF. Excerto de entrevista concedida em fevereiro de 2015).

Essa construção convergente foi facilitada pela anterioridade da experiência brasileira de reconhecimento institucional da agricultura familiar. O próprio governo brasileiro salienta que a Declaração de Aptidão ao Pronaf (DAP), instrumento de registro existente no Brasil, é "referência internacional entre os países do Mercosul." (Brasil, MDA, 2014:13). De fato, a resolução regional define critérios próximos daquelespresentes na DAP e na Lei da Agricultura Familiar (Lei $n^{\text {o } 11.326), ~ e s t a b e l e c i d a s, ~ r e s p e c t i v a m e n t e, ~ e m ~} 1997$ e 2006. A importante exceção é o critério referente ao uso dos recursos produtivos, os quais devem ser compatíveis com a capacidade de trabalho da família, com a atividade desenvolvida e com a tecnologia utilizada (Resolução GMC n 25/2007, art. 1). Ele não está presente na regulamentação brasileira, tendo sido incluído em virtude da pressão de países como Uruguai e Argentina. No entanto, até o momento, ele tem se mostrado de difícil manejo na delimitação de parâmetros objetivos de identificação. 
Uma vez acordada a definição comum, o passo seguinte foi a identificação dos agricultores. A construção dos Registros Nacionais Voluntários da Agricultura Familiar foi direcionada para um Grupo Técnico específico, que se voltouà operacionalização dos registros, ocupando, sobretudo, a agenda da burocracia estatal ${ }^{5}$. Nesse processo, observa-se que a experiência e os instrumentos da política pública (DAP) não foram simplesmente transferidos aos demais países. Diferentemente da cópia, o que se observou foi um processo de tradução ou, utilizando o conceito elaborado por Dolowitz e Marsh (2000) e reconhecido por Marin (2011), de "emulação" com as particularidades locais. As traduções manifestam-se na própria denominação adotada em cada país: Agricultor familiar (Brasil e Argentina); Agricultor Familiar Campesino (Paraguai) e Produtor Familiar (Uruguai). Note-se, por exemplo, que, enquanto a definição paraguaia acentua o caráter campesino da população rural, a noção uruguaia reconhece que a maioria dos estabelecimentos ruraisse dedica à pecuária, característica singular de sua história agrária.

As traduções tornam-se ainda mais evidentes nos parâmetros de registro. No Brasil, a DAP foi o mecanismo criado pelo governo em 1997 para garantir acesso exclusivo dos agricultores familiares ao Programa Nacional de Fortalecimento da Agricultura Familiar (Pronaf), e atualmente também serve de parâmetro para o acesso a um amplo conjunto de políticas públicas. Após diversas modificações, mas ainda coerente com a definição original, a DAP assegura condições mais restritivas que a Lei da Agricultura Familiar (Lei n ${ }^{\circ}$ 11.326/2006), abarcando apenas os agricultores que atendem aos seguintes critérios: a) exploram parcela de terra na condição de proprietários, posseiros, arrendatários, comodatários, parceiros, concessionários do Programa Nacional de Reforma Agrária, ou permissionários de áreas públicas; b) residem no estabelecimento ou em local próximo, considerando as características geográficas regionais; c) não detêm área superior a quatro módulos fiscais; d) detêm, no mínimo, 50\% da renda bruta originária da exploração agropecuária e não agropecuária do estabelecimento; e) têm o trabalho familiar como predominante, utilizando mão de obra de terceiros de acordo com as exigências sazonais da atividade agropecuária, podendo manter empregados permanentes em número menor que o número de pessoas da família ocupadas com o empreendimento; f) obtiveram renda bruta familiar de até $\mathrm{R} \$ 360 \mathrm{mil}$ reais nos últimos doze meses. 
Além disso, associado ao registro individual, no final dos anos 1990 o Brasil também criou um instrumento de identificação das organizações da agricultura familiar, denominado DAP Jurídica. Em um primeiro momento, exigia-se que a pessoa jurídica fosse formada exclusivamente por agricultores familiares. No entanto, rompendo com concepções que presumiam a endogenia da categoria ou seu isolamento social, as regras tornaram-se menos rígidas. O percentual foi gradativamente reduzido até alcançar a proporção de $60 \%$ como limite mínimo de participação de agricultores familiares.

Uma pluralidade de organizações podem emitir as DAPs, com destaque para os Sindicatos de Trabalhadores Rurais e os órgãos de Assistência Ténica e Extensão Rural. Em termos operacionais, nos casos em que os agricultores podem se deslocar até as organizações de registro, elas mesmas aplicam um questionário que é encaminhado para validação junto ao MDA. Nos demais casos, há uma ação mais proativa dos técnicos, incluindo mutirões de documentação, para alcançar agricultores em comunidades mais isoladas. Ademais, para além do controle e da validação de informações que ocorre pelos próprios agentes públicos e organizações sociais implicadas, as DAPs podem ser objeto de um controle social nos Conselhos Municipais de Desenvolvimento Rural Sustentável (Niederle, 2016).

Na Argentina, a discussão sobre os registros da agricultura familiar também é anterior à Resolução GMC 25/2007, ainda que fortemente influenciada pelas discussões que já estavam em curso na REAF. Com a criação do Fórum Nacional da Agricultura Familiar (Fonaf) em 2006, começou a delinear-se um Registro Nacional. Em 2007, no bojo dos debates e decisões da REAF, a então Secretaria de Agricultura, Pecuária, Pesca e Alimentos publicou a Resolução no 255 que cria o Registro Nacional da Agricultura Familiar (Renaf) como "o único meio pelo qual os agricultores familiares poderão acessar os benefícios dos instrumentos de políticas públicas diferenciadas para o setor". Mais recentemente, a Lei $\mathrm{n}^{\circ}$ 27.118/2015 (art. 6), estabeleceu a obrigação dos Agricultores e Agricultoras Familiares registrarem-se de forma individual e associativa para serem incluídos como beneficiários das políticas.

A unidade de registro é o Núcleo Agricultor Familiar (NAF), que consiste na pessoa ou no grupo de pessoas, parentes ou não, que habitam sob um mesmo teto em um regime de tipo familiar, isto é, comparti- 
lham seus gastos em alimentação ou outros bens essenciais para viver, e que aportem ou não força de trabalho para o desenvolvimento de alguma atividade no âmbito rural. Para o caso de população indígena, o conceito equivale ao de comunidade. Ademais, são considerados NAF todas as famílias ou estabelecimentos de produtores agropecuários, florestais, pescadores, coletores e/ou com atividades artesanais, agroindustriais ou turísticas que utilizem recursos de origem agrária, sem importar se o destino dessas atividades é a venda, o autoconsumo ou a troca, ou se é a atividade principal ou secundária, considerando a adequação aos seguintes critérios: a) vivam em áreas rurais ou a uma distância que permita contatos frequentes com a produção agrária ou conexas; b) a mão de obra ocupada corresponda predominantemente à família e seja limitada a contratação de mão de obra; c) a renda de fora do estabelecimento seja limitada a um máximo de três salários mínimos de peão rural por mês; d) assumam a responsabilidade/controle sobre sua atividade produtiva. Note-se que a principal diferença do registro argentino em relação a todos os demais é que ele não estabelece limites de área para a agricultura familiar.

A responsabilidade do registro está a cargo da Unidade de Registro Nacional da Agricultura Familiar. O preenchimento dos formulários é feito por registradores habilitados pertencentes às organizações de agricultores familiares e técnicos de campo da Secretaria de Agricultura Familiar do Ministério da Agricultura, Pecuária e Pesca (MGAyP). Os dados levantados são averiguados e controlados em várias instâncias (local, provincial e nacional). Atendidos todos os critérios, a listagem dos agricultores registrados é publicada na internet tornando-se sujeita ao controle social.

A Argentina também implantou um instrumento específico para identificação das organizações coletivas. O Registro Nacional de Organizações da Agricultura Familiar (Renoaf) é voluntário e não abarca critérios de formalização jurídica. Os requisitos mínimos de registro exigem que a organização detenha, no mínimo, dez integrantes e, ao menos, $70 \%$ do quadro de sócios ou cooperados devem cumprir os requisitos de agricultor familiar estabelecidos pelo Renaf.

O Paraguai foi, de acordo com Carvalho (2011:120), “o primeiro país a, depois da Resolução 25/2007, começar a implementar o registro de agricultores familiares, ainda em 2007, com o nome de Registro Nacional da Agricultura Familiar (Renaf)". No entanto, o "registro foi 
realizado na mesma época de uma entrega de subsídios para perdas por fenômenos climáticos [Certificado Agrícola], criando confusão entre a população, que associou o preenchimento dos dados para o registro ao recebimento dos subsídios". Em virtude dessa confusão, "apenas em 2010 o governo paraguaio finalmente reordenou o formulário, que tinha problemas, e previa recomeçar a coleta de dados" (Carvalho, 2011:116). Durante a realização desta pesquisa, esse processo estava em andamento sob responsabilidade do Departamento de Registro da Agricultura Familiar na Direção de Censos e Estatísticas Agropecuárias (DCEA).

Seguindo parâmetros mais estritos que aqueles estabelecidos pela Lei $n^{\circ}$ 2.419/2004 - que define a "agricultura familiar campesina" -, o Renaf considera passível de registro: a) a atividade produtiva rural que se executa utilizando principalmente a força de trabalho familiar; b) que, além disso, não contrata no ano um número maior do que 20 diaristas assalariados de maneira temporária; c) que reside na propriedade e/ou em comunidades próximas; d) que não utiliza, sob qualquer condição (propriedade, arrendamento etc.), mais que 50 hectares na Região Oriental e 500 hectares na Região Ocidental. Por sua vez, o país não conta com um registro específico para as organizações coletivas até o momento.

No Uruguai, teve início um primeiro esforço de delimitação conceitual com fins de intervenção do Estado em 2006. Impulsionado pelos debates da REAF, esse esforço resultou na Resolução no 527/2008 do MGAP, que apresentou uma primeira definição de "produtores familiares". Ela foi atualizada em 2014 por meio das Resoluções Ministeriais $n^{\text {os }} 219$ e 387, as quais estabelecem que produtores/as familiares são pessoas físicas que, com ou sem a ajuda de outras, administram diretamente uma exploração agropecuária e/ou realizam uma atividade produtiva agrária que não requer o uso direto da terra. Essa pessoa, em conjunto com sua família, deve cumprir os seguintes critérios: a) realizar a exploração do estabelecimento com a colaboração de, no máximo, dois assalariados permanentes ou seu equivalente em jornadas em safra (500 ao ano); b) explorar até 500 hectares (Coneat 100); c) residir na exploração ou a uma distância menor que 50 km dela; d) deter renda familiar nominal extraestabelecimento menor ou igual a $14 \mathrm{BPC}^{6}$ mensais em média. 
O registro uruguaio consiste em uma declaração jurada a partir de um formulário padronizado por produtor (e não pela unidade familiar de produção, como no Brasil). As atividades de Registro foram iniciadas em 2009. Desde então, o registrose tornou a "ferramenta principal que tem a institucionalidade pública agropecuária uruguaia para a aplicação de políticas diferenciadas para a produção familiar a nível nacional." (Sganga, Cabrera e Gonzalez, 2013:2). Embora inicialmente o Registro tenha sido impulsionado pela possibilidade de diferenciar um segmento para acessar benefícios de renúncia fiscal do Estado associados ao tema da seguridade social, atualmente esse instrumento baliza um amplo conjunto de ações públicas. Em 2014, a Lei n ${ }^{\circ} 19.292$, que trata das compras públicas da agricultura familiar, também estabeleceu o Registro Nacional de Organizações Habilitadas (Renaoh) como ferramenta de identificação das organizações coletivas aptas a entregar produtos ao Estado e a acessar outras políticas.

Em suma, pode-se verificar que a experiência brasileira serviu de base para construir os parâmetros de definição da agricultura familiar em âmbito regional; no entanto, os demais países se apropriaram das ideias para estruturar seus próprios arranjos normativos e sistemas de registro. Eles diferem tanto no que tange ao conceito utilizado quanto em questões operacionais relacionadas aos limites de área, rendimento e mão de obra. Além disso, também existem diferenças relativas à estrutura e ao funcionamento dos organismos responsáveis pelo registro, bem como aos seus mecanismos de controle social dos mesmos.

\section{OS PROGRAMAS DE COMPRAS PÚBLICAS DA AGRICULTURA FAMILIAR: DA CONVERGÊNCIA NA AGENDA PARA A TRADUÇÃO NOS INSTRUMENTOS}

O tema das compras públicas de produtos da agricultura familiar adentrou as discussões da REAF em 2010. Na ocasião, o GT de Facilitação do Comércio vivenciavaum momento de redefinição da agenda, haja vista que o tema da liberalização do comércio havia se tornado um tanto periférico no debate político regional. Assim, procurando redinamizar o diálogo sobre alternativas de comercialização, e inspirados pela experiência brasileira com os chamados "mercados institucionais", o Grupo decidiu analisar as potencialidades das compras públicas como mecanismos de inclusão e garantia de mercado para a agricultura familiar. Como relata um gestor da Direção Geral de Desenvolvimento Rural do Uruguai, 
O debate sobre compras públicas na região foi impulsionado desde o Brasil, a partir do PAA e do PNAE, dois programas enormes e que foram exitosos. Então, o Brasil colocou a temática na mesa, no GT de Comércio, e isso foi levantado pelos países na medida da necessidade de cada país e da agenda política de cada país. (Gestor público do governo do Uruguai. Excerto de entrevista concedida em abril de 2015).

Em face de sua experiência com o Programa de Aquisição de Alimentos (PAA) e o Programa Nacional de Alimentação Escolar (PNAE), foi, sobretudo, o governo brasileiro quem capitaneou a discussão. $\mathrm{O}$ tema avançou significativamente durante a XIV REAF, realizada em 2010. A reunião foi precedida pelo Seminário sobre Aquisição Pública de Alimentos da Agricultura Familiar, onde foram discutidas as experiências brasileiras. Em parceira com a Agência Brasileira de Cooperação, inicialmente o MDA propôs um projeto de cooperação técnica intitulado "Intercâmbio de Experiência sobre Modelos de Gestão da Política de Compras Públicas da Agricultura Familiar". Organizado em quatro módulos entre 2011 e 2013, o intercâmbio contou com a participação de gestores governamentais e representantes da sociedade civil de Argentina, Brasil, Paraguai, Uruguai, Chile e Equador. A partir da avaliação positiva do projeto e da entrada de novos países no debate, a REAF decidiu dar seguimento à iniciativa por meio de uma segunda edição. Realizados em diferentes países, os módulos contaram com apresentação das experiências nacionais e discussão dos arranjos organizacionais e institucionais, sendo importantes para a difusão de ideias e convergência de políticas.

Atualmente já é possível notar importantes iniciativas em curso em diferentes países do Mercosul, sobretudo no que tange às inovações normativas para viabilizar o tratamento diferenciado dispensado à agricultura familiar nos novos mercados institucionais. Ademais, pode-se perceber que, se a experiência brasileira foi o ponto de partida da discussão, isso não implica, contudo, a replicação direta nos demais países. Em cada contexto, os instrumentos estão sendo traduzidos para os diferentes quadros institucionais que regulam a ação do Estado, bem como para a realidade da agricultura familiar local.

No Brasil, em 2003 o governo federal lançou o PAA com vistas a promover a articulação entre a agricultura familiar - por meio do apoio à comercialização - e organizações públicas e privadas dedicadas a atender as necessidades de consumo de grupos em situação de vul- 
nerabilidade social. Em termos gerais, o Estado compra alimentos do sagricultores familiares e os destina a populações em situação de insegurança alimentar (Grisa et al., 2011). Alguns anos depois, em 2009, mudanças realizadas na Lei 11.947/2009 alteraram o funcionamento do PNAE e passaram a exigir que no mínimo 30\% dos recursos do Fundo Nacional de Desenvolvimento da Educação (FNDE) repassados ao Programa sejam destinados à aquisição de alimentos da agricultura familiar. Em 2015, o governo federal também estabeleceu o Decreto $\mathrm{n}^{\circ} 8.473$, que estabelece a obrigatoriedade de aquisição de no mínimo 30\% de gêneros alimentícios da agricultura familiar quando da compra de alimentos por parte da Administração Pública Federal. Em ambos os programas, as aquisições são realizadas por meio de Chamadas Públicas (ou seja, sem licitação). Trata-se de uma espécie de "edital público" em que consta o conjunto de alimentos demandados e as condições de participação (preços, qualidade etc.). Para participar os agricultores familiares devem apresentar a DAP, ao passo que as organizações devem possuir DAP Jurídica.

Na Argentina, as compras públicas de bens e serviços são realizadas pelo Escritório Nacional de Contratações por meio de licitações, à exceção de compras diretas (Decreto ${ }^{\circ} 1.023 / 2001$ ) de pessoas físicas ou jurídicas inscritas no Registro Nacional de Realizadores de Desenvolvimento Local e Economia Social, visando sua inclusão no mercado formal. Em 2010, a criação do Monotributo Social Agropecuário (MSA), gratuito, formalizou o reconhecimento institucional da agricultura familiar como ator da economia social no âmbito rural. Tornou-se, então, possível a inclusãodos agricultores ao Registro Nacional de Realizadores de Desenvolvimento Local e Economia Social e, consequentemente, a comercialização de seus produtos por meio da compra direta. No entanto, o limite de comercialização por agricultor é relativamente baixo, enfraquecendo a participação da agricultura familiar (Mosse, 2017; Durmrauf et al., 2015). Com a Lei de Reparação Histórica da Agricultura Familiar em 2014 (Lei n ${ }^{\circ}$ 27.118), que a estabelece como fornecedora prioritária de alimentos para os equipamentos públicos, as compras públicas ganharam maior institucionalidade. No entanto, as mudanças políticas nacionais ocorridas em 2015 criaram dificuldades para a institucionalização e regulamentação desses dispositivos.

No Paraguai, os instrumentos de aquisição pública de produtos da agricultura familiar são recentes. O Decreto n ${ }^{\circ} 1.056$ de 2013 estabele- 
ceu uma modalidade de contrato complementar chamado "Processo Simplificado para Aquisição de Produtos Agropecuários da Agricultura Familiar". Abarcando todos os níveis federativos, a normativa permitia a realização de compras diferenciadas dos agricultores familiares campesinos e suas organizações por meio de Carta Convite. No entanto, em 2015, diante de um contexto de questionamentos políticos em relação ao normativo, o Decreto n ${ }^{\circ} 1056 / 2013$ foi substituído pelo Decreto $\mathrm{n}^{\circ} 3.000$, provocando mudanças institucionais e incrementos burocráticos que dificultam a participação da agricultura familiar e ampliam as compras indiretas (Caldas e Ávila, 2017; Riquelme, 2016; Mila, 2015). No caso paraguaio também é importante destacar a Lei ${ }^{\circ}$ 5.210/2012 sobre alimentação escolar, que prioriza a aquisição de alimentos da agricultura familiar. Esse procedimento se aplica em caráter de exceção às disposições estabelecidas nos quadros regulamentares vigentes para os Contratos Públicos (Lei n ${ }^{\circ} 2.051 / 2003$ ) e para a Administração Financeira do Estado (Lei n $\left.{ }^{\circ} 1.535 / 1999\right)$.

No Uruguai, as discussões sobre compras públicas também nasceram impulsionadas pelos diálogos regionais e desembocaram, primeiramente, em um projeto piloto implantado em 2010. Ele consistiu em uma tentativa de organizar os produtores familiares e suas organizações para disputar as licitações públicas, que é o mecanismo utilizado pelo Estado uruguaio para aquisição de produtos e serviços. No entanto, como destacou um gestor público entrevistado, esse mecanismo logo se revelou inadequado à realidade dos produtores familiares, o que fez com que o projeto exibisse resultados muito aquém do esperado. Mesmo assim, serviu como ensaio para mudanças institucionais futuras. Em 2014, o governo uruguaio estabeleceu a Lei n $19.292 / 2014$, a partir da qual a "produção familiar agropecuária e pesca artesanal se declara de interesse geral e se estabelece um mecanismo de reserva de mercado estatal de bens e serviços alimentícios". Esse normativo também estabelece que somente podem participar as organizações dos produtores familiares (ou seja, de forma coletiva), as quais devem ser compostas por, pelo menos, cinco produtores, sendo que, no mínimo, 70\% devem ser familiares.

No caso das políticas de compras públicas, o processo de transferência poderia ser compreendido como uma mescla de emulação e inspiração dependendo do país analisado. Em algumas situações, a experiência brasileira ofertou ideias e exemplos que serviram para estruturar programas similares, inclusive no que tange aos percen- 
tuais de reserva de mercado para a agricultura familiar. Em outras, seria mais adequado falar em inspiração, haja vista que os programas criados possuem formatos bastante distintos dos originais, refletindo fatores institucionais que restringem um processo completo de transferência, bem como o interesse dos atores em inovar na construção das políticas públicas em face dos seus próprios referenciais e constrangimentos institucionais.

\section{CONSIDERAÇÕES FINAIS}

Neste artigo, discutimos a atuação da REAF como mediadora dos processos de transferência de políticas públicas para a agricultura familiar no Mercosul. Trata-se de um espaço singular cujas características ainda foram pouco exploradas pela literatura internacional sobre policy transfer, que geralmente aborda processos e dinâmicas de transferência em relações bilaterais entre blocos econômicos e/ ou organizações e movimentos internacionais. A contribuição principal do artigo aos estudos da temática reside justamente em discutir os processos de transferência, convergência e tradução no âmbito do fórum de um bloco econômico, que integra sociedade civil e Estado e cujas relações mostram-se mais dialógicas e menos assimétricas e coercitivas.

Os dois casos selecionados para análise - registros nacionais e compras públicas - demonstram protagonismo do Brasil. A escolha de outros exemplos poderia conferir maior visibilidade a outros países, mas ainda assim, dificilmente colocaria em dúvida a ideia de que o Brasil, pela sua própria trajetória de reconhecimento institucional da agricultura familiar, capitaneou o processo. Do ponto de vista histórico, a sociogênese da REAF ratifica essa conclusão.

O aspecto fundamental é que o que acontece no âmbito da REAF não configura uma dinâmica unilateral de transferência onde prevalecem os tradicionais mecanismos de pressão utilizados pelo Norte Global para imporsuas "boas instituições" de governança (Chang, 2004). Ao contrário, há um engajamento mais voluntário do que em outros espaços de disseminação internacional de políticas públicas: não apenas os governos e os movimentos sociais revelam uma ação pró-ativa para alcançar inserção nos diálogos regionais, como outros fóruns (CELAC, Unasul) e algumas organizações multilaterais (FIDA, FAO) procuram a REAF para estruturar ações de cooperação. Mais do que 
um espaço público, a REAF também se tornou um "ator coletivo" que domina capacidades técnicas e incide na agenda regional, estabelecendo ainda uma espécie de ponte entre organizações globais e governos nacionais.

É importante considerar que também existem assimetrias de poder nos diálogos políticos regionais. O fato, por exemplo, de o Brasil ter sido responsável por $70 \%$ dos recursos do FAF conferiu-lhe uma importante margem de negociação para a definição da agenda da REAF. Mas isso não culminou na imposição de regras, instrumentos ou modelos, como ocorreu em outros contextos. Como vimos acima, a definição normativa de agricultura familiar adotada pelo bloco e traduzida pelos países difere daquela existente no Brasil, haja vista que alguns países incorporam estabelecimentos com extensões que não se enquadram na definição brasileira. No caso das compras públicas, nota-se, por exemplo, que o mesmo tipo de política foi adequado a diferentes contextos institucionais, o que fica demonstrado pela existência de distintos instrumentos em cada país: chamada pública (Brasil), carta convite (Paraguai), licitação (Uruguai). Isso foi possível porque, mesmo lançando mão de instrumentos mandatórios como Resoluções e Decisões, o que poderia sugerir um processo muito mais coercitivo, a maioria das regras é maleável de modo a permitir adequações a contextos nacionais.

Assim, a experiência da REAF revela a construção de um projeto de integração regional que, a partir de uma coalizão de governos de centro-esquerda (Niederle, 2016), facilitou processos que mesclam difusão, transferência, convergência e tradução de políticas públicas. Na realidade, essa especificidade implica convergência de agendas políticas, difusão e transferência de ações e importante tradução de políticas públicas, como visto nos casos do Registro da Agricultura Familiar e das Compras Públicas da Agricultura Familiar.

Dentre os principais fatores que constrangeram avanços mais céleres nos processos de transferência, convergência e tradução, destaca-se, por um lado, a instabilidade institucional vivenciada por alguns países nos últimos anos e, por outro, a desestruturação da coalizão política que amparou a construção de um Mercosul Social e Participativo. No que tange à instabilidade institucional, pode-se destacar, por exemplo, as crises que seguiram a suspensão do Paraguai (2012) e da Venezuela (2016) do bloco em virtude de desacordo dos demais 
países sobre o cumprimento da chamada "cláusula democrática" do Mercosul (Monte e Anastasia, 2017). Embora as organizações sociais daqueles países tenham mantido presença na REAF, a ausência de governo implicou elevado nível de instabilidade institucional, restringindo a tomada de decisões que, no futuro, poderiam ser questionadas - o que, de fato, ocorreu logo após o cancelamento da suspensão imposta ao Paraguai.

Soma-se a isso a instabilidade interna de cada país, associada aos processos mais ou menos abruptos de ruptura entre o paradigma social-desenvolvimentista que orientou as discussões nos primeiros ciclos da REAF e aquele que vem se consolidando na região com a ascensão de governos liberais e conservadores. Os reflexos mais imediatos dessa mudança foram a extinção dos antigos ministérios e secretarias que se ocupavam da pauta da agricultura familiar em cada país, a redução dos recursos para as políticas públicas voltadas ao segmento (incluindo os programas de compras públicas), a ascensão de uma política externa contrária ao multilateralismo e a desintegração dos espaços de participação social. Tais mudanças começam a repercutir em fortes questionamentos, não apenas sobre a manutenção da REAF (que, em 2017, já se expressaram no fim do FAF), mas sobre o próprio reconhecimento da agricultura familiar, campesina e indígena. Abre-se, portanto, uma agenda de pesquisa que não focaliza mais o processo de difusão das políticas, mas os mecanismos por meio dos quais os diferentes países estão em vistas de ajustá-las ou desconstruí-las. Seriam similares as estratégias, os discursos e as vias institucionaisutilizadas em cada caso? Essa é uma das questões que orientam nossa atual agenda de pesquisa.

(Recebido para publicação em agosto de 2016)

(Reapresentado em novembro de 2017)

(Reapresentado em janeiro de 2019)

(Aprovado para publicação em fevereiro de 2019) 


\section{NOTAS}

1. Alguns desses elementos conceituais também foram discutidos em Grisa e Niederle (2018) e Grisa, Perafán e Calderón (2018).

2. Neste estudo, compreende-se difusão como o processo pelo qual uma inovação é comunicada para membros de um sistema social por meio de intermediários, ganhando relevância a análise de elementos psicossociais da comunidade "alvo", a influência de grupos externos, o papel da mídia e dos meios de comunicação (Rogers, 1971).

3. Enquanto as Decisões, Resoluções e Diretrizes possuem caráter obrigatório para os Estados Membros, a incorporação das Recomendações aos ordenamentos jurídicos nacionais é voluntária.

4. Nas demais Reuniões Especializadas, a participação social geralmente se resume a convites pontuais a especialistas e lideranças sociais para intervenções em temas específicos.

5. Cabe destacar que o tema que concentrou maior atenção nos diálogos políticos foi o reconhecimento mútuo dos registros; isso implica cada país reconhecer os agricultores familiares identificados pelos demais. Tal reconhecimento mútuo foi aprovado pela Decisão $\mathrm{CMC} \mathrm{n}^{\circ}$ 20/2014, também de caráter obrigatório, a qual incorpora ainda procedimentos e rotinas de monitoramento dos registros.

6. A "Base Ficta de Contribución" é um padrão fiscal uruguaio calculado para pagamento de tributos. 


\section{REFERÊNCIAS BIBLIOGRÁFICAS}

ANCELOVICI, Marcos; JENSON, Jane. (2012), "La standardisation et les mecanismes du transfert transnational“. Gouvernement et Action Publique, n. 1, pp. 37-58.

BEARD, Victoria; MIRAFTAB, Faranak; SILVER, Christophe. (2008), Planning and Decentralization: contested spaces for public action in global south. London, New York: Routledge.

BENSON, David; JORDAN, Andrew. (2011), “What have we Learned from Policy Transfer Research? Dolowitz and Marsh revisited". Political Studies Review, v. 9, n. 3, pp. 366-378.

BRASIL. (2008), Mercosul social e participativo. Brasília.

BRASIL. MINISTÉRIO DO DESENVOLVIMENTO AGRÁRIO. (2014), Manual do agente emissor de Declaração de Aptidão ao Pronaf. Versão 1.0. Brasília (DF): MDA.

CALDAS, Eduardo L.; ÁVILA, Mário L. (2017) Compras públicas e alimentação escolar no Paraguai: a disseminação da experiência brasileira e a adaptação do modelo. Trabalho apresentado no XIX Congresso da ALACIP. Montivedeo, Julho de 2017.

CALLON, Michael. (1998), "Introduction: the embeddedness of economic markets in economics". In: (org.). The laws of the markets. Oxford: Blackwell.

(1984), "Some elements of a sociology of translation: domestication of scallops and the fishermen of St Brieuc Bay". The Sociological Review, v. 32, n. 1, pp. 196-233.

CAMACHO, Tatiana S. (2011),Teorias de transferência de políticas públicas: um estudo crítico e ilustrado com o caso da transferência do Bolsa Escola para o Equador. Dissertação (Mestrado em Desenvolvimento Econômico), Universidade Federal do Paraná, Curitiba.

CARVALHO, Patrícia D. (2011), Ação coletiva transnacional e o Mercosul. Dissertação (Mestrado em Ciência Política), Universidade de Brasília, Brasília.

CASTELLS, Manuel. (2005), “A sociedade em rede: do conhecimento à política”. In: M. Castells; G. Cardoso (orgs.), A Sociedade em Rede: do conhecimento à acção política. Lisboa: Imprensa Nacional.

CASTRO, Carolina; GOULET, Frederic. (2011), “L'essor des coopérations sud-sud: le Brésil en Afrique et le cas du secteur agricola". Techniques Financiéres et Développement, n. 105 , pp. $87-102$.

CHANG, Ha-Joon. (2004), Chutando a escada: a estratégia do desenvolvimento em perspectiva histórica. São Paulo: UNESP.

COELHO, Denilson B.; CAVALCANTE, Pedro; TURGEON, Mathieu. (2016), "Mecanismos de difusão de políticas sociais no Brasil: uma análise do Programa Saúde da Família". Revista de Sociologia e Política, v. 24, n. 58, pp. 145-165.

DOLOWITZ, David P. (2003) A policy-maker's guide to policy transfer. Political Quarterly, v. 74, n. 1, pp.101-108.

; MARSH, David. (2000), Learning from abroad: the role of policy transfer in contemporary policy-making. Governance: An International Journal of Policy and Administration, v. 13, n. 1, pp. 5-23. 
(1996), Who learns what from whom: a review of the policy transfer literature, Political Studies, v. 44, pp. 343-57.

DURMRAUF, Sergio et al. (2015), Compras públicas a la agricultura familiar. Trabalho apresentado na VII Jornadas interdisciplianarias de studios agrarios y agroindustriales, Buenos Aires.

EVANS, Mark. (2004), Policy transfer in global perspective. London, New York: Routledge.

EVANS, Peter. (2003), "Além da monocultura institucional: instituições, capacidades e o desenvolvimento deliberativo". Sociologias, v. 5, n. 9, pp. 20-63.

FARIA, Carlos A.P. (2012), A difusão de políticas sociais como estratégia de inserção internacional: Brasil e Venezuela comparados. Interseções, v. 14, pp. 335-371.

; COELHO, Denilson B.; SILVA, Sidney J. (2016), Difusão de políticas públicas. São Bernardo do Campo: EduUFABC.

FOOD AND AGRICULTURE ORGANIZATION OF THE UNITED NATIONS. (2015), Global dialogue on family farming. Rome: FAO.

(2014), The state of food and agriculture: innovation in family farming. Rome.

FUNDO INTERNACIONAL DE DESENVOLVIMENTO AGRÍCOLA (FIDA).(2013), Medidas adoptadas en los cuatro países fundadores del Mercosur, vinculadas a debates y recomendaciones formuladas por la REAF. Montevideo: FIDA Mercosul.

GOULET, Frederic; GABAS Jean-Jacques; SABOURIN, Eric. (2013), “Brazilian and Chinese Cooperation in African Agriculture": A Practice-based Study. Íconos, v. 47, pp. 87-100.

GRISA, Catia; NIEDERLE, Paulo A. (2018), “Difusão, convergência e tradução nas políticas de compras públicas da agricultura familiar no âmbito da REAF Mercosul". Mundos Plurales, v.3, n.2, pp. 9-30.

GRISA, Catia; PERAFÁN, Mireya E.V.; CALDERÓN, Patrícia G. (2018), Transferência e tradução de políticas públicas do Brasil para a Colômbia: o caso das compras públicas da agricultura familiar. Estudos: Sociedade e Agricultura, v. 26, n. 2, pp. 353-375.

GRISA, Catia; SCHNEIDER, Sérgio. (2015), Políticas públicas de Desenvolvimento Rural no Brasil. Porto Alegre: Editora da UFRGS.

et al. (2011), Contribuições do Programa de Aquisição de Alimentos à segurança alimentar e nutricional e à criação de mercados para a agricultura familiar. Agriculturas, v. 8, n. 3, pp. 34-41.

HASSENTEUFEL, Patrick. (2008), Sociologie politique: l'action publique. 2 ed. Paris: Armand Colin.

(2005), De la comparaison international à la comparaison transnationale: les déplacements de la construction d'objets comparatives en matière de politiques publiques. Revue Française de Science Politique, v. 55, pp. 113-132.

; et al. (2017), Policy difusion and translation. Novos Estudos CEBRAP, v. 36, pp. 77-96.

; MAILLARD, Jacques. (2013), "Convergence, transferts et traduction: les apports de la comparaison transnationale". Gouvernement et Action Publique, v.3, pp. 377-393. 


\section{Catia Grisa, Paulo Niederle}

KNILL, Christoph. (2005), "Introduction: cross-national policy convergence: concepts, approaches and explanatory factors". Journal of European Public Policy, v. 12, n. 5, pp. 764-774.

LASCOUMES, Pierre. (2006), "Traduction“. In: L. Boussguet; S. Jacquot; P. Ravinet (orgs.), Dictionnaire des politiques publiques. 2 ed. Paris: Sciences Po. Les Presses, p. 439-445.

; LE GALÉS, Patrick. (2012), "Ação pública abordada pelos seus instrumentos". Revista Pós Ciências Sociais, v. 9, n. 18, pp. 19-44.

(2007), "Introduction: understanding public policy through its instruments - from the nature of instruments to the sociology of public policy instrumentation". Governance: an International Journal of Policy, Administration and Institutions, v. 20, n.1.

LATOUR, Bruno. (1994), “On technical mediation: philosophy, sociology and genealogy”. Common Knowledge, v. 3, pp. 29-64.

LEVI-FAUR, David; VIGODA-GADOT, Eran. (2004), The international transfer and diffusion of policy and management innovations: some characteristics of a New Order in the making. In: (eds.), International Public Policy and Management: Policy Learning Beyond Regional, Cultural and Political Boundaries, Marcel Dekker.

LONG, Norman. (2001), Development sociology: actor perspectives. London: Routledge.

MALUF, Renato; SANTARELLI, Mariana; PAULINO, G. (2016), Cooperação Sul-Sul em SAN, mobilidade e transferência de políticas. Textos para discussão 11, Ceresan.

McCANN, Eugene; WARD, Kevin. (2013), “A multi-disciplinary approach to policy transfer reserach: geographies, assemblages, mobilities and mutations". Policy Studies, v. 34, n. 1, pp. 2-28.

. (2012), "Policy assemblages, mobilities and mutations: toward a multidisciplianry conversation". Political Studies Review, v. 10, n. 3, pp. 325-332.

MARIN, Pedro L. (2011), Mercosul e a disseminação internacional de políticas públicas. Cadernos Gestão Pública e Cidadania, v. 16, n. 58, pp. 7-22.

MILAN, Fabián. (2015), La agricultura familiar como proveedora de las compras públicas de productos agrícolas y alimentos. Documento de Trabajo. Seminário Taller.

MILHORANCE, Carolina. (2013), “A política de cooperação do Brasil com a África Subsaariana no setor rural: transferência e inovação na difusão de políticas públicas". Revista Brasileira de Política Internacional, v. 56, n.2, pp. 5-23.

MITCHELL, William C.; SIMMONS, Randy T. (2003), Para além da política: mercados, bem-estar social e o fracasso da burocracia. Rio de Janeiro: Topbooks.

MONTE, Deborah; ANASTASIA, Fátima. (2017), “Cláusula democrática do Mercosul: indefinição conceitual e uso estratégico". Revista de Sociologia e Política, v. 25, n. 62, pp. 11-36

MOSSE, Luis. (2017), La construcción de um sector. Políticas para la agricultura familiar en Argentina, 2002-2015. Dissertação de Mestrado em Ciências Sociais.

NIEDERLE, Paulo A. (2016), REAF Mercosur: una década de coproducción de políticas públicas entre el Estado y la Sociedad Civil. Santiago: FAO. 
OLIVEIRA, Osmany P. (2013), Embaixadores da participação: a difusão internacional do Orçamento Participativo a partir do Brasil. Tese (Doutorado em Ciência Política). São Paulo: USP.

; FARIA, Carlos A.P. (2017), "Policy transfer, diffusion and circulation". Novos Estudos CEBRAP, v. 36, pp. 13-32.

PEREIRA, João M.M. (2009), O Banco Mundial como ator político, intelectual e financeiro (19442008). Tese (Doutorado em História). Niterói-RJ: UFF.

PINHO, Carlos Eduardo Santos. (2013), “Cooperación sur-sur para el desarrollo: las relaciones Brasil-Afria em la promoción de las políticas públicas (2003-2012)". América Latina Hoy, n. 63, pp. 91-112.

RAMOS, Alvaro. et al. (2014), "El desarrollo institucional de la agricultura familiar en el MERCOSUR: La experiencia de la REAF”. In: S. Salcedo; L. Guzmán (eds.), Agricultura familiar em América Latina y el Caribe: Recomendaciones de Política. Santiago: FAO.

RIELLA, Alberto. (2002), "Las organizaciones rurales y el proceso de integración regional". Revista de Ciencias Sociales, v. 20, n. 15, pp. 75-86.

RIQUELME, Quintín. (2016), Agricultura familiar campesina en el Paraguay: notas preliminares para su caracterización y propuestas de desarrollo rural. Documento de Trabajo. Asunción: Centro de Análisis y Difusión de la Economía Paraguaya.

ROGERS, Everett M. (1971), Diffusion of innovations. New York: The Free Press.

ROMANO, Jorge O. (1996), “Atores e processos sociais agrários no MERCOSUL”. Estudos Sociedade e Agricultura, v. 6, pp. 91-113.

SABOURIN, Eric; SAMPER, Mario; MASSARDIER, Gilles. (2015), As políticas de desenvolvimento rural na América Latina em perspectiva. In: C. Grisa; S. Schneider (orgs.), Políticas públicas de Desenvolvimento Rural no Brasil. Porto Alegre: Editora da UFRGS.

SANTOS, Boaventura de Sousa. (2002), "Para uma sociologia das ausências e uma sociologia das emergências". Revista Crítica de Ciências Sociais, v. 63, pp. 237-280.

SCHMITT, Claudia Job; MALUF, Renato.(2010), "Soberania e segurança alimentar no Mercosul Ampliado: o lugar da agricultura camponesa e familiar". In: R. Moreira; R. Bruno (orgs.), Interpretações, estudos rurais e política. Rio de Janeiro: EDUR-Mauad X, pp. 133155.

SCOONES, Ian; AMANOR, Kojo; FAVARETO, Arilson; GUBO, Qi. (2016), “A new politics of development cooperation? Chinese and Brazilian Engagements in Africa Agriculture". World Development, v. 81, pp. 1-12.

SERRES, Michel. (1993), Filosofia mestiça. Rio de Janeiro: Nova Fronteira.

SGANGA, Fernando; CABRERA, Cecília; GONZALEZ, M. (2013), “Estado de situación del Registro de Productores Familiares como herramienta para la aplicación de políticas públicas para el desarrollo rural". Anuario OPYPA, Uruguay.

STONE, Diane. (2012), "Transfer and translation of policy". Policy Studies, v. 33, n. 6, pp. 483-499. 


\section{Catia Grisa, Paulo Niederle}

(2007), "Public policy analysis and think thanks". In: FISCHER, Frank; MILLER, Gerald; SIDNEY, Mara. Handbook of public policy analysis: theory, politics, and methodos. Boca Raton: Taylor \& Francis Group.

. (2004), "Transfer agents and global networks in the 'transnationalisation' of policy. Journal of European Public Policy, v. 11, n. 3, pp. 545-566.

VIGEVANI, Tullo; RAMANZINI JUNIOR, Haroldo. (2014), “Autonomia, integração regional e política externa brasileira: Mercosul e Unasul”. DADOS, v. 57, n. 2, pp. 517-552.

WALKER, Jack. (1969), "The diffusion of innovations among the American States". The American Political Science Review, v. 63, n. 3, pp. 880-899.

WILKINSON, John. (2008), Mercados, redes e valores. Porto Alegre: UFRGS. 


\section{RESUMO}

Transferência, Convergência e Tradução de Políticas Públicas: A Experiência da Reunião Especializada sobre Agricultura Familiar do Mercosul

O artigo analisa a atuação da Reunião Especializada sobre Agricultura Familiar (REAF) como fórum público e ator coletivo que coordena um processo de construção, transferência e tradução de políticas de desenvolvimento rural no Mercosul. O objetivo consiste em analisar o modo como ideias, políticas e instrumentos de ação pública para a agricultura familiar são transferidos no âmbito da REAF, enfatizando os atores envolvidos e suas relações no processo de decisão, bem como o modo como as políticas convergem ou são traduzidas nos espaços nacionais. Os dados são provenientes da observação de encontros regionais, pesquisa documental e entrevistas com gestores públicos e lideranças sociais dos países do bloco. Os resultados demonstram como a REAF forjou um espaço para a transferência voluntária de políticas públicas que, mesmo conduzindo à convergência de ideias e instrumentos de políticas públicas para a agricultura familiar com protagonismo do Brasil como principal país "exportador", permitiu flexibilidade para tradução e adaptação das políticas nos espaços locais.

Palavras-chave: agricultura familiar; Mercosul; políticas públicas; transferência.

\section{ABSTRACT \\ Transfer, Convergence, and Translation of Public Policies: The Experience of the Special Meeting on Family Agriculture of Mercosur}

The article analyzes the work of the Specialized Meeting on Family Agriculture (REAF) as a public forum and collective actor that coordinates a process of construction, transfer, and translation of rural development policies in Mercosur. The goal is to analyze how ideas, policies and instruments of public action for family agriculture are transferred within the framework of REAF, emphasizing the actors involved and their relations in the decision-making process, as well as the way in which policies converge or are translated to national spaces. The data comes from the observation of regionais meetings, documentary research, and interviews with public managers and social leaders of the member countries. The results demonstrate how the REAF forged a space for the voluntary transfer of public policies that, even leading to the convergence of ideas and instruments of public policies for family agriculture with Brazil as the main "exporting" country, allowed flexibility for translation and adaptation policies in local spaces.

Keywords: family agriculture; Mercosur; public policies; transfer. 


\section{RESUME}

Transfert, Convergence et Traduction de Politiques Publiques: L'Expérience de la Réunion Extraordinaire sur l'Agriculture Familiale du Mercosur

L'article analyse les performances de la Réunion Spécialisée sur l'Agriculture Familiale (REAF) en tant que forum public et acteur collectif qui coordonne un processus de construction, de transfert et de traduction de politiques de développement rural dans le Mercosur. L'objectif est d'analyser la manière dont les idées, les politiques et les instruments d'action publique en faveur de l'agriculture familiale sont transférés dans le cadre de la REAF, en mettant l'accent sur les acteurs impliqués et leurs relations dans le processus décisionnel, ainsi que sur la manière dont les politiques convergent ou sont traduites dans les espaces nationaux. Les données proviennent d'observations de réunions régionales, de recherches documentaires et d'entretiens avec des responsables publics et des responsables sociaux des pays du bloc. Les résultats démontrent comment la REAF a créé un espace pour le transfert volontaire de politiques publiques qui (en conduisant à la convergence des idées et des instruments des politiques publiques pour l'agriculture familiale avec le protagonisme du Brésil en tant que principal pays «exportateur») a permis une flexibilité pour la traduction et l'adaptation des politiques dans les espaces locaux.

Mots-clés : agriculture familiale; Mercosur; politiques publiques; transfert.

\section{RESUMEN}

Transferencia, Convergencia y Traducción de Políticas Públicas: La Experiencia de la Reunión Especializada sobre Agricultura Familiar del Mercosur

El artículo analiza la actuación de la Reunión Especializada sobre Agricultura Familiar (REAF) como foro público y actor colectivo que coordina un proceso de construcción, transferencia y traducción de políticas de desarrollo rural en el Mercosur. El objetivo consiste en analizar el modo en el que ideas, políticas e instrumentos de acción pública para la agricultura familiar son transferidos en el ámbito de la REAF, dando énfasis a los actores involucrados y sus relaciones en el proceso de decisión, así como en el modo en que las políticas convergen o son traducidas en los espacios nacionales. Los datos son provenientes de la observación de encuentros regionales, investigación documental y entrevistas con gestores públicos y líderes sociales de los países del bloque. Los resultados demuestran que la REAF forjó un espacio para la transferencia voluntaria de políticas públicas que, a pesar de conducir la convergencia de ideas e instrumentos de políticas públicas para la agricultura familiar con protagonismo de Brasil como principal país "exportador", permitió flexibilidad para la traducción y adaptación de las políticas en los espacios locales.

Palabras clave: agricultura familiar; Mercosur; políticas públicas; transferencia. 